\title{
New way of purification of pathogenic rickettsiae reducing health risks
}

\author{
J. VALÁRIKOVÁ, Z. SEKEYOVÁ, L. ŠKULTÉTY, M. BOHÁCSOVÁ, M. QUEVEDO-DIAZ*
}

\author{
Department of Rickettsiology, Institute of Virology, Biomedical Research Center, Slovak Academy of Sciences, Dúbravská cesta 9, \\ 84505 Bratislava, Slovak Republic
}

Received February 4, 2016; accepted April 25, 2016

\begin{abstract}
Summary. - In general, cultivation and purification of intracellular pathogenic rickettsiae represents a risk for laboratory personnel due to exposure to highly infectious aerosol or accidental inoculation during these procedures. In this study, we describe an alternative, effective and time saving technique for rickettsial purification using digitonin to release intracellular bacteria from host cell without physical disruption. No significant differences were noted in yield and infectivity between digitonin treated rickettsiae and rickettsiae purified by sonication. This is the first report of using digitonin in purification of pathogenic rickettsiae and this approach might be effective for other intracellular pathogenic bacteria.
\end{abstract}

Keywords: Rickettsia akari; Rickettsia conorii; digitonin; purification

\section{Introduction}

Rickettsiae are gram negative obligate intracellular bacteria which proliferate within the cytoplasm of eukaryotic cells. In humans, pathogenic rickettsiae cause diverse diseases such as Typhus, Rickettsialpox, Mediterranean spotted fever (MSF), Rocky Mountain spotted fever (Parola et al. 2005). Rickettsia akari and Rickettsia conorii, the etiological agents of Rickettsialpox and Mediterranean spotted fever respectively, are commonly distributed in Southern and Eastern Europe (Brouqui et al., 2007). Presence of $R$. akarii was mainly identified in Croatia (Radulovic et al., 1996), Turkey (Ozturk et al., 2003) and Serbia (Samardizic et al., 2008) whereas R. conorii was described throughout Europe, especially in Mediterranean area (Raoult et al., 1986). These organisms exhibited high infectivity in animals (Walker et al., 1994; Sammons et al., 1977). Therefore, work with rickettsial pathogens requires biosafety level 3 laboratory procedures including propagation and other manipulation with these microorganisms.

Rickettsiae are usually propagated in yolk sacs of embryonated chicken eggs or in laboratory animals, but cultivation in

${ }^{*}$ Corresponding author. E-mail: virumaqd@savba.sk; phone: +4212-59302430.

Abbreviations: $\mathrm{GE}=$ genome equivalent mammalian cell cultures is preferred (Policastro et al., 1997). Immortal cell lines like Vero (African green monkey kidney epithelial cells), L929, endothelial and epithelial cells (HeLa) are commonly employed to grow rickettsiae (Ammerman et al., 2008). Owing to intracellular nature of rickettsia, rupture of cell membrane is essential for purification of bacteria from host cell debris. Different cell lysis methods have been used in purification of rickettsiae including sonication and shearing by passage through a syringe needle (Ammerman et al., 2008). After cell lysis, highly purified rickettsia is achieved by isopycnic density gradient centrifugation (Weiss et al., 1975). However, these methods are extremely time-consuming and this way of manipulation with BSL3 pathogens can be potentially hazardous for laboratory personnel. A novel method of disruption of host cells was developed for purification of another intracellular bacteria Coxiella burnetti employing digitonin, a cytotoxic non-ionic steroid detergent, which disrupts permeability of membranes and facilitates bioavailability and uptake of polar substances to cell (Eid et al., 2012), showed that yield of bacteria was comparable with sonication and that treatment with digitonin did not affect infectivity of bacteria (Cockrell et al., 2008). In this study, we describe the use of digitonin in purification of pathogen Rickettsia under biosafety level 3 conditions. This method showed similar effect in cell lysis comparable to sonication routinely employed for purification procedure. 


\section{Materials and Methods}

Rickettsial strain, host cells and growth condition. The Vero76 cell line (ATCC CRL-1587) was grown in DMEM (Dulbecco's modified Eagle's medium with $4.5 \mathrm{~g}$ glucose/liter with glutamine; Lonza) supplemented with $10 \%$ fetal bovine serum (Lonza) and incubated at $37^{\circ} \mathrm{C}$ in presence of $5 \% \mathrm{CO}_{2}$. Rickettsia akari, the Kaplan strain and Rickettsia conorii subsp. caspia were propagated in Vero76 cells in biosafety level 3 laboratory as previously described (Ammerman et al., 2008). Rickettsial stock solutions were prepared from $10\left(175 \mathrm{~cm}^{2}\right)$ infected flasks, partially purified using Ultravist 370-cushion and quantified by RT-qPCR. Rickettsiae were stored in aliquots containing $1 \times 10^{7}$ rickettsiae per $1 \mathrm{ml}$ at $-80^{\circ} \mathrm{C}$ until use.

Rickettsial purification by digitonin and sonication. Digitonin treatment was performed as described previously (Cockrell et al., 2008) with a small modification. A monolayer of Vero cells was infected either with R. akari or R. conorii at a multiplicity of infection of approximately 50 in T-25 flask. Rickettsia-infected Vero cells were incubated at $34^{\circ} \mathrm{C}$ and $5 \% \mathrm{CO}_{2}$ for 4 days. Culture medium from infected cells was removed and washed with SP buffer $(12.8 \mathrm{mmol} / \mathrm{l}$ $\mathrm{KH}_{2} \mathrm{PO}_{4}, 72.6 \mathrm{mmol} / \mathrm{l} \mathrm{NaCl}, 53.9 \mathrm{mmol} / \mathrm{l} \mathrm{Na}_{2} \mathrm{HPO}_{4}, \mathrm{pH}$ 7.4) containing $250 \mathrm{mmol} / \mathrm{l}$ sucrose. Five milliliters of SP buffer containing digitonin $(0.2 \mathrm{mg} / \mathrm{ml})$ were added to each flask with gentle rocking at room temperature for $30 \mathrm{~min}$. Soluble and insoluble cell debris was transferred to a $15 \mathrm{ml}$ conical tube and placed on ice.

For sonication lysis, infected cells were harvested from flask and pelleted by centrifugation at $22,000 \mathrm{x} g$ for $30 \mathrm{~min}$ at $4^{\circ} \mathrm{C}$. Supernatant was discarded and pellet was resuspended in SP buffer on ice. Host cell lysis was achieved by three 20 sec pulses at setting 6 using a Sonifer Cell disruptor (Model SLPe, Branson Ultrasonic Co., USA). After this step, digitonin treated and sonicated samples were further processed identically. Cell debris and unbroken cells were separated from released bacteria by centrifugation at $900 \mathrm{x}$ g for $5 \mathrm{~min}$ at $4^{\circ} \mathrm{C}$. Supernatants containing free bacteria were transferred to a clean tube and centrifuged at 23,000 $\mathrm{xg}$ for $15 \mathrm{~min}$. Supernatant was removed and pellets were resuspended in SPG buffer $(218 \mathrm{mmol} / \mathrm{l}$ sucrose, $3.8 \mathrm{mmol} / 1 \mathrm{KH}_{2} \mathrm{PO}_{4}, 7.2 \mathrm{mmol} / 1 \mathrm{~K}_{2} \mathrm{HPO}_{4}, 4.9 \mathrm{mmol} / \mathrm{l} \mathrm{L}$-glutamate, $\mathrm{pH} 7.2$ ) and overlaid onto $25 \%$ solution (v/v) of Ultravist 370 (Bayer Pharma AG) in SPG buffer. Tubes were centrifuged at 17,000 $\mathrm{x} g$ for $20 \mathrm{~min}$ at $4^{\circ} \mathrm{C}$. After centrifugation the most host cell debris remains at Ultravist/SPG interface while rickettsia resides in the bottom of the tube. Pellet was resuspended in cold SPG and transferred into the clean tube and centrifuged at 23,000 $\mathrm{x} g$ for $15 \mathrm{~min}$. Pellet was processed for RNA isolation or it was resuspended in SPG buffer and stored at $-80^{\circ} \mathrm{C}$ for further procedures.

$R N A$ isolation and RT-qPCR procedure. Total RNA was isolated using the Qiagen RNAeasy micro kit (Qiagen, USA) according to manufacturer's instructions. RNA was DNAse treated and repurified with RNeasy MinElute cleanup kit (Qiagen, USA). Reverse transcription was performed from isolated RNA using the First strand cDNA synthesis kit (Thermo Scientific, USA). For rickettsial quantification, two-step, RT-qPCR technique was employed using specific primers and TaqMan probe for $r p s L$ gene (F: 5'-CCCGGT
GAAAAGCATAGTGT-3'; R: 5'-ATTTCACACCCGGAAGATCA-3'; Probe: 5'FAM-TTAGTAAGAGGCGGTCAGGTG-TAMRA3'). Each $25 \mu \mathrm{l}$ reaction mixture contained $25 \mathrm{ng}$ of cDNA, 2x Maxima Probe qPCR master mix (Thermo Scientific, USA), $250 \mathrm{nmol} / \mathrm{l}$ concentrations of each primer and $200 \mathrm{nmol} / \mathrm{l}$ of fluorescent probe. The qPCR was performed in a CFX.96 Real Time system (Biorad, USA) with the following conditions: $95^{\circ} \mathrm{C}$ for $10 \mathrm{~min} ; 40$ amplification cycles of $95^{\circ} \mathrm{C}$ for $30 \mathrm{sec}, 58^{\circ} \mathrm{C}$ (annealing temperature) for $40 \mathrm{sec}$, and $72^{\circ} \mathrm{C}$ for $40 \mathrm{sec}$. For every run, each sample was tested in triplicate.

Indirect immunofluorescence test. Purified bacteria and Vero cells containing rickettsiae were fixed on slides with $3.7 \%$ formaldehyde in PBS for $15 \mathrm{~min}$ at RT, permeabilized with $0.1 \%$ Triton X-100 in PBS for 7 min at RT, washed with PBS and blocked with 5\% BSA in PBS for $1 \mathrm{hr}$ at $37^{\circ} \mathrm{C}$. After washing, cells were incubated with a rabbit antiserum against Rickettsia (1:100) diluted in 2.5\%BSA/ PBS for $1 \mathrm{hr}$ at $37^{\circ} \mathrm{C}$. After washing, cells were incubated with goat anti-rabbit IgG secondary antibody conjugated with Alexa fluor 488 (Life technologies, USA) diluted 1:1000 in PBS containing $2.5 \%$ BSA. Coverslips were mounted with Vectashield (Vector Laboratories) containing DAPI and analyzed using fluorescence microscopy (model Eclipse Ni, Nikon, Japan).

\section{Results}

\section{Digitonin lysis of host cells infected with rickettsiae}

Vero cell monolayers were infected with $R$. akari and $R$. conorii for a period of 4 days, during this time the rickettsiae reached stationary phase of growth and optimal yields of bacteria for purification. Subsequently, infected cell monolayers were treated with SP buffer containing digitonin at concentration of $0.2 \mathrm{mg} / \mathrm{ml}$ as described above. A time course observation during this treatment by microscopy showed complete dissolution of cell monolayer after $30 \mathrm{~min}$ (Fig. 1).

\section{Comparison of yield and infectivity of purified rickettsial cells}

Rickettsia akari and R. conorii cells were purified employing both digitonin and sonic disruption protocols respectively. Subsequently, RNA from both rickettsial species was extracted, transcribed to cDNA and quantified using RT-qPCR. To determine yield of bacteria, we compared genome equivalents (GE) of rickettsiae after sonication and digitonin treatment. The average of three replicates is given in GE and it is shown in Table 1. Similar numbers of GE were detected for R. akari and $R$. conorii in both purification protocols $\left(2.8 \times 10^{7} / 1.9 \times 10^{7}\right.$ for digitonin lysis and $1.5 \times 10^{7} / 1.6$ $\mathrm{x} 10^{7}$ for sonification) respectively (Table 1 ).

To evaluate changes in infectivity of rickettsiae after digitonin treatment, fresh Vero cell monalayers were infected with rickettsiae purified using digitonin and sonication lysis procedures (Fig. 2a). Four days post infection, immunofluo- 


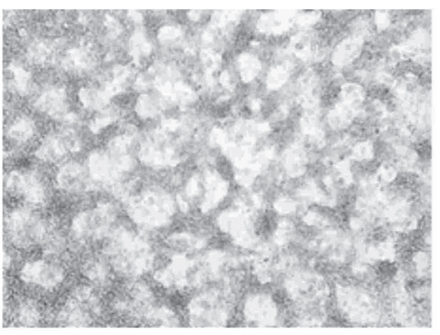

Pre-treatment

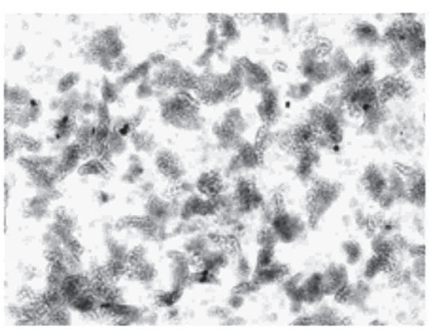

$0.2 \mathrm{mg} / \mathrm{ml}$ digitonin 15 min

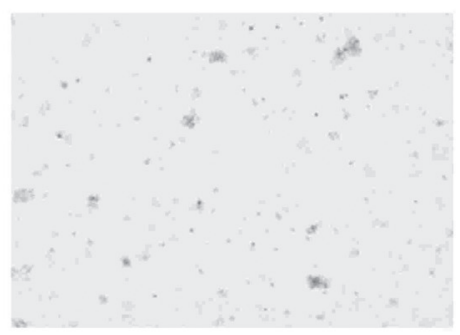

$0.2 \mathrm{mg} / \mathrm{ml}$ digitonin $30 \mathrm{~min}$

Fig. 1

Time course of dissolution of a Rickettsia-infected Vero cell monolayer after digitonin treatment Pre-treatment (time $0 \mathrm{~min}), 15 \mathrm{~min}$ after digitonin treatment $(0.2 \mathrm{mg} / \mathrm{ml}), 30 \mathrm{~min}$ after digitonin treatment $(0.2 \mathrm{mg} / \mathrm{ml})$.

Table1. Numbers of genome equivalents of $R$. akari and $R$. conorii employing sonication procedure and digitonin lysis

\begin{tabular}{llcc}
\hline \multirow{2}{*}{ Species } & \multicolumn{2}{c}{ Genome equivalents (GE) } \\
\cline { 3 - 4 } & & Digitonin & Sonication \\
\hline Purified bacteria & R. akari & $2.8 \times 10^{7}$ & $1.5 \times 10^{7}$ \\
& R. conori & $1.9 \times 10^{7}$ & $1.6 \times 10^{7}$ \\
\hline Reinfection & R. akari & $8.6 \times 10^{7}$ & $1.3 \times 10^{8}$ \\
& R. conori & $3.2 \times 10^{7}$ & $4.4 \times 10^{7}$ \\
\hline
\end{tabular}

rescence assay showed presence of rickettsiae inside the Vero cells indicating that rickettsiae remain viable after digitonin treatment (Fig. 2b).
Interestingly, comparable numbers of GE in $R$. conorii after digitonin treatment and sonication (in average $3.2 \mathrm{x}$ $10^{7}$ and $4.4 \times 10^{7}$ ) were observed respectively. However, GE of $R$. akari was slightly increased in sample after sonication $\left(1.3 \times 10^{8}\right)$ in comparison with sample after digitonin treatment $\left(8.6 \times 10^{7}\right)$.

\section{Discussion}

The need to utilize embryonated eggs or cell culture techniques for the propagation of Rickettsia spp. includes extensive purification procedures. Sonication is normally
Alexa Fluor 488

(a)

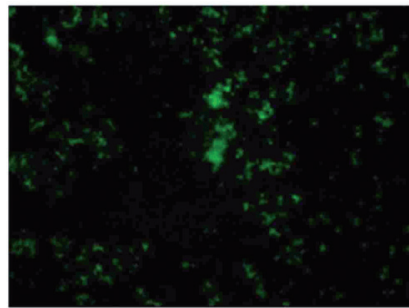

(b)

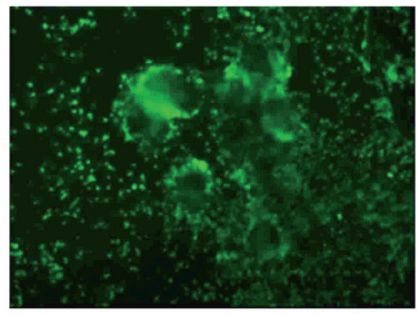

DAPI
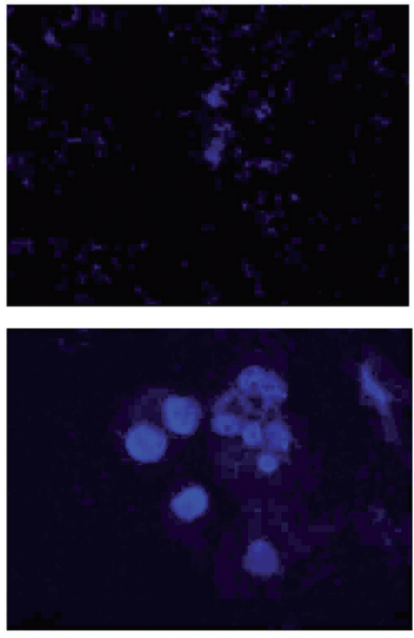

Fig. 2
MERGE
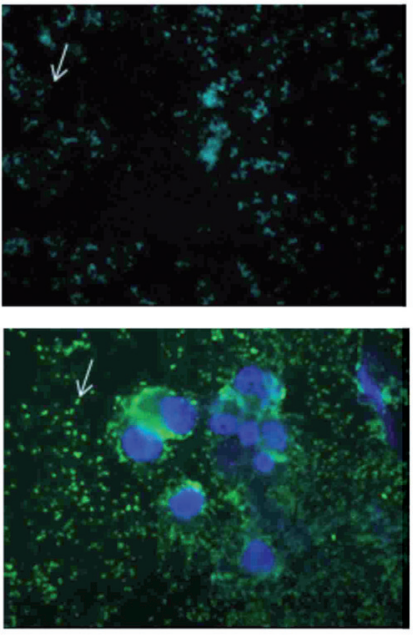

Immunofluorescent staining of purified R. akari and Rickettsia-infected Vero cells

Purified Rickettsia after digitonin treatment stained by Alexa Fluor 488 (a). Vero cells infected with digitonin-purified R. akari four days post infection. DAPI stained Vero cells and rickettsial DNA (b). Arrows show rickettsial cells. Magnification $1000 \mathrm{x}$. 
used to release rickettsia (Ammerman et al., 2008) and other intracellular pathogen like Coxiella burnetii (Shannon and Heizen, 2008) and Chlamydiaceae (Li et al., 2005) from host cells. Disadvantage of this procedure is production of infectious aerosol during sonication, which is potentially hazardous for laboratory personnel. However, cases of laboratory- associated infections with rickettsia were reported (Pike, 1976). Center for Disease Control and Prevention (CDC, 1978) documented three cases of murine typhus related to handling with infectious material and accidental parenteral inoculation. Oster et al. (1977) reported nine cases that occurred in a period of six years in one laboratory and these cases were associated with Rickettsia rickettsii aerosol transmission.

Therefore a new method using chemical disruption is needed to minimize risk of infection for laboratory workers. Digitonin molecules bind specifically to cholesterol in the host cell membrane and forms cholesterol-digitonin complexes on the membrane surface by removing cholesterol from the membrane core (Frenkel et al., 2014). In process of rickettsial attachment cholesterol plays important role as component of cholesterol containing host cell receptors (Walker et al., 1983, Ramm and Winkler, 1983). Accordingly, we were interested in potential changes in infectivity caused by residual digitonin in samples. Immunofluorescence assay results demonstrated no changes in infectivity caused by residual digitonin in samples and entry into host cell proceeds normally.

In summary, digitonin treatment of Rickettsia akari and Rickettsia conorii is effective alternative technique in comparison with sonication procedure of host cell lysis and release of intracellular bacteria from host cell. No significant differences in yield and infectivity of bacteria treated with digitonin and sonication were noticed. Due to potential risk of sonication where highly infectious aerosol is produced, is digitonin lysis of host cells safe and effective alternative to sonication and is suitable not only for Coxiella burnetti as well for R. akari and R. conorii.

Acknowledgement. This study was supported by the grants VEGA: 2/0193/12 from the Scientific Grant Agency of Ministry of Education of Slovak Academy of Sciences, contract No. APVV-0280-12 of Slovak Research and Development Agency.

\section{References}

Ammerman NC, Beier-Sexton M, Azad AF (2008): Laboratory maintenance of Rickettsia rickettsii. Curr. Protoc. Microbiol. Chapter unit 3A.5.

Brouqui P, Parola P, Fournier PE, Raoult D (2007): Spotted fever rickettsioses in southern and eastern Europe. FEMS Immunol. Med. Microbiol. 49, 2-12. http://dx.doi. org/10.1111/j.1574-695X.2006.00138.x
Centers for Disease Control and Prevention (1978): Laboratoryacquired endemic typhus. MMWR Morb. Mortal. Wkly. Rep. 27, 215-216.

Cockrell DC, Beare PA, Fischer ER, Howe D, Heinzen RA (2008): A method for purifying obligate intracellular Coxiella burnetii that employs digitonin lysis of host cells. J. Microbiol. Methods 72, 321-325. http://dx.doi.org/10.1016/j. mimet.2007.12.015

Eid SY, El-Readi MZ, Wink M (2012): Digitonin synergistically enhances the cytotoxicity of plant secondary metabolites in cancer cells. Phytomedicine 19, 1307-1314. http:// dx.doi.org/10.1016/j.phymed.2012.09.002

Frenkel N, Makky A, Sudji IR, Wink M, Tanaka M (2014): Mechanistic investigation of interactions between steroidal saponin digitonin and cell membrane models. J. Phys. Chem. B 118, 14632-14639. http://dx.doi.org/10.1021/ jp5074939

Li D, Vaglenov A, Kim T, Wang C, Gao D, Kaltenboeck B (2005): High-yield culture and purification of Chlamydiaceae bacteria. J. Microbiol. Methods 61, 17-24. http://dx.doi. org/10.1016/j.mimet.2004.10.020

Ozturk MK, Gunes T, Coker C, Radulovic S (2003): Rickettsialpox in Turkey. Emerg. Infect. Dis. 9, 1498-1499. http://dx.doi. org/10.3201/eid0911.030224

Oster CN, Burke DS, Kenyon RH, Ascher MS, Harber P, Pedersen CE Jr (1977): Laboratory-acquired Rocky Mountain spotted fever. The hazard of aerosol transmission. N. Engl. J. Med. 297, 859-863. http://dx.doi.org/10.1056/ NEJM197710202971604

Parola P, Paddock CD, and Raoult D (2005): Tick-borne rickettsioses around the world: emerging diseases challenging old concepts. Clin. Microbiol. Rev. 18, 719-756. http://dx.doi. org/10.1128/CMR.18.4.719-756.2005

Pike RM (1976): Laboratory-associated infections: Summary and analysis of 3,921 cases. Health Lab. Sci.13, 105-114.

Policastro PF, Munderloh UG, Fischert ER, Hackstadt T (1997): Rickettsia rickettsii growth and temperatureinducible protein expression in embryonic tick cell lines. J. Med. Microbiol. 46, 839-845. http://dx.doi. org/10.1099/00222615-46-10-839

Radulovic S, Feng HM, Morovic M, Djelalija B, Popov V, CrocquetValdes P, Walker DH (1996): Isolation of Rickettsia akari from a patient in a region where Mediterranean spotted fever is endemic. Clin. Infect. Dis. 22, 216-220. http:// dx.doi.org/10.1093/clinids/22.2.216

Ramm LE, Winkler HH (1983): Identification of cholesterol in the receptor site for rickettsiae on sheep erythrocyte membranes. Infect. Immun. 13, 120-126.

Raoult D, Wieller PJ, Chagnon A, Chaudet H, Gallais H, Casanova P (1986): Mediterreanean spotted fever: Clinical, laboratory and epidemiological features of 199 cases. Am. J. Trop. Med. Hyg. 35, 845-850.

Samardzic S, Marinkovic T, Marinkovic D, Djuricic B, Ristanovic E, Simovic T, Lako B, Vukov B, Bozovic B, Gligic A (2008): Prevalence of antibodies to Rickettsiae in different regions of Serbia. Vector Borne Zoonotic Dis. 8, 219-224. http:// dx.doi.org/10.1089/vbz.2007.0122 
Sammons LS, Kenyon RH, Hickman RL, Pederson CE Jr (1977): Susceptibility of laboratory animals to infection by spotted fever group rickettsiae. Lab. Anim. Sci. 27, 229-234.

Shannon JG, Heinzen RA (2008): Infection of human monocytederived macrophages with Coxiella burnetii. Methods Mol. Biol. 431, 189-200. http://dx.doi.org/10.1007/9781-60327-032-8 15

Walker DH, Firth WT, Ballard JG, Hegarty BC (1983): Role of phospholipase-associated penetration mechanism in cell injury by Rickettsia rickettsii. Infect. Immun. 40 , 840-842.

Walker DH, Popov VL, Wen J, Feng HM (1994): Rickettsia conorii infection of $\mathrm{C} 3 \mathrm{H} / \mathrm{HeN}$ mice. A model of endothelialtarget rickettsiosis. Lab. Invest. 70, 358-368.

Weiss E, Coolbaugh JC, Williams C (1975): Separation of viable rickettsia typhi from yolk sac and L cell host components by renografin density gradient centrifugation Appl. Microbiol. 30, 456-463. 